\title{
Comunidad de Comunidades: los judíos en México
}

Community of Communities: Jews in Mexico

Renne Dayan

renee.dayans@gmail.com

Directora de Tribuna Israelita

México

Deborah Roitman

debyroitman@gmail.com

Colaboradora Centro de Estudios Judaicos

Universidad de Chile

\section{Resumen}

Inmigrantes judíos llegados a México durante la primera mitad del siglo XX, formaron comunidades de acuerdo a sus lugares de origen, un estilo de vida que persiste hasta del día de hoy. Formaron una comunidad altamente organizada y cohesionada, bajo un alto rango de bienestar, que incluye servicios religiosos, educativos, culturales y más. Así mismo, en sus más de 100 años de vida han lograron una alta concurrencia de sus niños a la red escolar judía y un bajo índice de matrimonios exogámicos, evitando la asimilación. Actualmente sus integrantes, se consideran sumamente integrados a la sociedad mexicana, la cual son parte. Este artículo es de orden descriptivo, donde se intenta exponer a la comunidad judía de México, abarcando diversas áreas que la constituyen.

Palabras clave: comunidad judía - México - historia judía moderna - asimilación. 


\section{Abstract}

Jewish immigrants who arrived in Mexico during the first half of the 20th century, formed communities according to their places of origin, a lifestyle that persists to this day. They formed a highly organized and cohesive community, under a high rank of well-being, that includes religious, educational, cultural services and more. Likewise, in there more than 100 years of life they have achieved a high attendance of their children to the Jewish school network and a low index of exogamous marriages, avoiding the assimilation. Today its members are considered highly integrated to the Mexican society, which are a part. This article is of descriptive order, where it tries to expose the Mexican Jewish community, covering diverse areas that constitute it.

Key words: Jewish community - Mexico - Jewish Modern history - Mexico - assimilation.

\section{Introducción}

La comunidad judía de México, con poco más de 100 años de su fundación, es una de las comunidades de la diáspora que se ha mantenido vigorosa, con una fuerte pertenencia, mostrando un alto índice de continuidad con poca asimilación. Sus integrantes están arraigados al país, tanto en lo referente al área laboral como a su cultura.

La idea de este articulo ha sido la de relatar acerca de la historia de la presencia de los judíos en México, partiendo desde la época de la Colonia, seguido por la creación de la comunidad a principios del siglo XX. Se continúa con una visión panorámica de cómo ha evolucionado la comunidad en temas relevantes como la creación de comunidades - de aquí el título del artículo-, la educación, la inserción laboral, la percepción de identidad religiosa, la asimilación, el antisemitismo y el sionismo. Será una descripción de estas variables sin profundizar en cada una de ellas, aunque en algunos casos, se refuerza la información, con datos duros obtenidos de dos encuestas comunitarias, del 2000 una y del 2015, la otra. 
Finalmente, se indican cuáles serían los desafíos que tiene por delante la comunidad judeomexicana para el siglo XXI.

\section{Historia}

\section{Etapa: Época colonial}

Los primeros judíos en tierras aztecas llegaron con Hernán Cortés en 1519, pocos años después de que se decretara el Edicto de Expulsión de España en 1492. Durante gran parte del período colonial continuaron arribando judíos provenientes de Europa y de América del Sur en calidad de criptojudíos ${ }^{1}$, huyendo de la Inquisición en la Península Ibérica y, posteriormente, cuando se impuso la Inquisición en Portugal.

En su nuevo hogar, los inmigrantes buscaban la libertad religiosa prohibida en sus lugares de origen; sin embargo en estas tierras también se hizo presente la Inquisición, que a pesar de que no se manifestó con la fuerza con que se dio en España, sin duda tuvo su propio poder.

Durante el siglo XVII se generó en la Nueva España una intensa persecución y se decretaron numerosos Autos de Fe en contra de criptojudíos y herejes. La intolerancia religiosa y el fuerte sentimiento de ser perseguidos mermaron la presencia de estos grupos. La exogamia, la carencia de estructura comunitaria y, con el tiempo, la falta de conocimientos de su religión, provocaron que los criptojudíos, finalmente, se fueran igualando a la población general.

Todos estos factores, aunados al hecho de que durante la Colonia la entrada de judíos estaba prohibida (a menos que ocultaran su religión o comprobaran su "limpieza de sangre"), contribuyeron a la desaparición de esta población de tal forma que, al consumarse la independencia de México en 1821, ya estaban totalmente asimilados a la sociedad mayoritaria.

\footnotetext{
1 Los criptojudíos -también denominados "marranos"- mantenían una doble identidad: públicamente se desempeñaban como cristianos, pero en el ámbito privado -en secreto- practicaban el judaísmo.
} 


\section{Etapa: Siglo XIX - principios del XX}

Años después de que México obtuviera su independencia, se promulgaron leyes que permitieron a las minorías no católicas inmigrar y recibir la nacionalidad, a la vez que se les otorgó la libertad de culto.

A mediados del siglo XIX, llegó al país Maximiliano de Habsburgo, Archiduque de Austria, quien con el apoyo de Napoleón III, intentó convertirse en Emperador de México. Junto con él arribaron judíos procedentes, en su mayoría, de Francia, Alsacia, Bélgica y Austria. Durante las últimas dos décadas de ese siglo, con Porfirio Díaz en el poder, el país inició su etapa de industrialización. Varios judíos europeos vinieron como representantes de empresas y/o como hombres de negocios. Lo peculiar de estos individuos es que no manifestaron su condición judía, ni se congregaron en comunidad durante su estancia en el país. Muchos de ellos regresaron a sus países de origen y quienes se quedaron terminan fusionándose con la población local, dejando atrás su ya débil identidad judía.

\section{Etapa: Orígenes De La Comunidad Judía Actual - Siglo XX}

\section{Migración}

En los últimos años del siglo XIX y principios del XX, huyendo de las condiciones de marginación económica y social en la que vivían, llegó al país una ola migratoria de judíos que conformaría los cimientos de la comunidad judía actual. Los primeros en arribar procedían de los Balcanes, Grecia, Turquía y Bulgaria, así como de Siria y Líbano; posteriormente llegarían de Europa Central y Oriental (Hamui, 2007).

Durante este período las políticas migratorias mexicanas eran relativamente flexibles y había un fácil acceso al país. De hecho, en 1924 el presidente Plutarco Elías Calles extendió una invitación a los judíos a venir a México en calidad de ciudadanos respetuosos de la ley (Zack de Zukerman, pp. 14-15). 
No obstante, para principios de la década de los treintas, el gobierno apoyó políticas restrictivas que limitaban la inmigración y aceptaban únicamente a grupos que fuesen fácilmente asimilables a la población y que protegiesen los intereses económicos de los ciudadanos (Gleizer, 2011, p. 321). Así, se limitó la entrada particularmente de rusos, polacos, turcos, judíos, húngaros y gitanos.

\section{Comunidad de comunidades}

En términos generales, los nuevos inmigrantes llegaban a México con la esperanza de una nueva vida teniendo que enfrentarse a un entorno totalmente nuevo y desconocido. Ante un país desgarrado por la Revolución de 1910, buscaron procurarse un sustento para vivir, a la vez de lograr garantizar la continuidad de sus tradiciones como sistema integral de vida.

En este proceso pusieron en práctica, una vez más, el concepto de autoayuda y solidaridad conformado a lo largo de su experiencia grupal y en torno al cual gravitan sus normas éticas y morales. De esto modo, constituyeron una comunidad, conscientes de que el individuo que desea preservar su identidad judía debe vivir en colectivo. Así fue que, a partir de su llegada a México, los inmigrantes judíos se organizaron con el fin de proporcionar servicios religiosos, educativos, legales, asistenciales, financieros y sociales a sus correligionarios, para continuar profesando su fe en el nuevo entorno y transmitir a las generaciones por venir su legado milenario.

La mayoría de las comunidades siguieron los modelos de las congregaciones que predominaban en sus países de origen. Sin embargo, al aumentar la inmigración procedente de Europa Oriental, antes de la Primera Guerra Mundial, surgió un cambio radical en los patrones organizacionales comunitarios. Los nuevos inmigrantes sustentaban ideologías políticas diferentes y muchos de ellos eran seculares. Esto dio pie a la creación de diversas organizaciones con motivaciones ya no específicamente religiosas, sino culturales, deportivas, educativas, entre otras.

No fue sino hasta 1912 y después de varios intentos, que los judíos radicados en México se agruparon en una sola organización llamada Sociedad de Beneficencia Alianza Monte Sinaí (Smeke y varios, 1965, pp. 35 y 93-94). La mayoría de los inmigrantes judíos de esa época eran 
de origen sirio, específicamente de la ciudad de Damasco. Su objetivo era el establecimiento de un cementerio judío, pero también se abocó a una amplia gama de actividades de beneficencia y apoyo. El permiso requerido para dicho cementerio fue concedido por Francisco I. Madero, presidente en turno, quien mantenía una estrecha amistad con Jacobo Granat, judío europeo que lo había apoyado en su campaña política. El reconocimiento, en términos legales, de la presencia de una comunidad judía organizada en México, se obtuvo recién en 1918, cuando el Presidente Venustiano Carranza otorgó personalidad jurídica a la Alianza Monte Sinaí.

El esfuerzo de agrupar a todos los judíos en una sola comunidad no fructificó, ya que las diferencias entre ashkenazíes ${ }^{2}$, judíos orientales ${ }^{3}$ y sefaradíes ${ }^{4}$ no se atenuaron al verse obligados a compartir una sola organización comunitaria. Por el contrario, parecía como si la convivencia avivara la conciencia de las particularidades donde cada sector traía su propio bagaje cultural y deseaba preservarlo. Por ello, consideraron más importante organizarse en términos étnicos y no como congregación religiosa. La sectorización se dio en función de la diversidad de países (incluso ciudades) de origen, y por tanto, de ritos y costumbres particulares: diversos lenguajes idish, ladino, árabe, diferencias en la interpretación de la liturgia, rituales, hábitos alimenticios y costumbres propias de cada región así como el énfasis en asuntos religiosos, culturales, ideológicos y/o políticos.

Esta división interna le ha merecido a la comunidad judeo-mexicana, como destacan Della Pergola y Lerner (1991), la denominación de "Comunidad de Comunidades": una comunidad subétnica cuya peculiaridad le confiere un carácter especial y la distingue de otras comunidades de la diáspora, donde los lugares de origen no han sido tan enfatizados ni logran una relevancia de tal magnitud.

Las comunidades que conforman la comunidad judía de la ciudad de México son las siguientes:

1. Sociedad de Beneficencia Alianza Monte Sinaí, creada en 1912, que agrupa a los

\footnotetext{
${ }^{2}$ Judíos provenientes de Europa central y oriental.

${ }_{4}^{3}$ Judíos provenientes del Líbano y Siria.

${ }^{4}$ Judíos provenientes del Imperio Otomano. 
judíos originarios de la ciudad de Damasco, Líbano e Israel. ${ }^{5}$

2. Comunidad Ashkenazí, fundada en 1922 como Kehilá Nidje Israel, conformada por judíos de origen europeo. ${ }^{6}$

3. Comunidad Maguén David, establecida en 1938, concentra a los judíos de la ciudad de Alepo, Siria. ${ }^{7}$

4. Comunidad Sefaradí, organizada formalmente en 1941 e integrada por judíos provenientes de Turquía, Grecia y los Balcanes.

Desde su creación, estas cuatro comunidades adoptaron la denominación religiosa de tipo ortodoxa.

A partir de la segunda mitad del siglo $\mathrm{XX}$ se constituyeron dos nuevas comunidades que a diferencia de las anteriores, se caracterizan por ser de denominación religiosa Conservadora y que, en su mayoría, están integradas por judíos de origen Ashkenazí:

5. Beth Israel Community Center, establecida en 1957 por judíos estadounidenses radicados en la ciudad de México.

6. Comunidad Bet-El, fundada en 1961, en gran parte como escisión del sector Ashkenazí, ya que algunos de sus miembros optaron por un judaísmo conservador.

\footnotetext{
${ }^{5}$ Para mayor información acerca de esta comunidad específicamente: Historia de una Alianza. Smeke, J y varios. Impresión y encuadernación: Turmex, Cda. De México, 1999.

${ }^{6}$ Para mayor información acerca de esta comunidad específicamente: Historia de la Comunidad Israelita de México 1917-1942. León Sourasky. Imprenta Moderna Pintel, Cdad. De México, 1965.

${ }^{7}$ Para mayor información acerca de esta comunidad específicamente: Esperanza y Realidad. Isaac Dabbah Askenazi. Editorial Libros de México, Cdad. De México, 1982.
} 
En 1950 se constituyó el Centro Deportivo Israelita (CDI), institución que ha logrado -desde sus inicios y hasta la actualidad- concentrar y vincular a judíos de todas las comunidades, con el deporte y la cultura como elementos aglutinadores.

Actualmente, cada una de las comunidades cuenta con instituciones educativas, sinagogas, baños rituales, Jebrá Kadisha (Servicios fúnebres), supervisión de kashrut (leyes alimenticias), Conciliación y Arbitraje, movimientos juveniles y centros comunitarios. Así mismo, ofrecen apoyo económico y realizan actividades sociales y culturales para sus miembros.

Con el transcurso del tiempo, las divisiones de acuerdo al origen geográfico se hicieron más flexibles y permeables. Esta transformación se aprecia en el aumento de matrimonios entre individuos que pertenecen a distintas comunidades, que llega al 60\%. La mayor parte de los judíos en México se casan al interior de la comunidad, esto provoca que el índice de matrimonios mixtos, según el estudio sociodemográfico de la población judía que realizaron Della Pergola y Lerner en 1991, es de entre 5 y $10 \%$.

Paralelamente, en la última década del siglo XX, se incrementaron en forma considerable las relaciones intercomunitarias en distintas áreas, circunstancia que se ve reflejada en la creación de diversas instituciones que dan servicio a todos los integrantes de la colectividad judía de México.

La población judía en México, para la primera década del siglo XXI, se calculaba en aproximadamente 40,000 almas. ${ }^{8}$ Se calcula, de acuerdo a datos del 2000, un total de 10180 familias. Aunque la gran mayoría de los judíos que radican en el país, están concentrados en la ciudad de México, otras ciudades también han sido polo de atracción para el establecimiento de pequeñas comunidades organizadas como lo son Guadalajara, Monterrey, Tijuana y Cancún. Estas colectividades cuentan, a su vez, con su sinagoga, escuela y centros recreativos propios.

8 http://www.enlacejudio.com/2011/01/07/numeros-judios/ 
Según el, el número de familias y su porcentaje por sector es el siguiente (Alduncín y Asociados, 2000):

$\begin{array}{llll}\text { Comunidad } & \text { \# Familias* } & \text { 2000* } & \text { 2015** } \\ \text { Maguén David: } & 2630 \text { familias } & 25.8 \% & 29.0 \% \\ \text { Monte Sinaí: } & 2350 \text { familias } & 23.0 \% & 26.9 \% \\ \text { Kehilá Ashkenazí: } & 1870 \text { familias } & 18.4 \% & 22.5 \% \\ \text { Comunidad Sefaradí: } & 1150 \text { familias } & 11.3 \% & 8.5 \% \\ \text { Bet El: } & 1080 \text { familias } & 10.6 \% & 8.7 \% \\ \text { CDI (no afiliados): } & 340 \text { familias } & 3.3 \% & 7.0 \% \\ \text { Bet Israel: } & 260 \text { familias } & 2.6 \% & 0.7 \% \\ \text { Comunidad Guadalajara: } & 250 \text { familias } & 2.5 \% & 1.1 \% \\ \text { Comunidad Monterrey: } & 250 \text { familias } & 2.5 \% & 0.9 \% \\ \text { Comunidad Tijuana: } & & 0.7 \% & 0.2 \% \\ \text { Comunidad Cancún: } & & 0.6 \% & 0.3 \%\end{array}$

*Alduncín y Asociados

** Estudio realizado por el Comité Central de la Comunidad Judía de México.

\section{Religión y tradición}

En lo que se refiere a la práctica religiosa, la mayoría de los judíos mexicanos se autodefine como tradicionalista. Esto implica que la pertenencia grupal se manifiesta básicamente en la participación en las instituciones judías (escuela, actividades sociales y culturales); en el mantenimiento de ciertas costumbres religiosas como la asistencia anual a la sinagoga en ocasión de las fiestas mayores y/o en la celebración religiosa de los momentos significativos del ciclo de vida judío como el Brit-Milá (circuncisión del varón a los 8 días de nacido), el Bar/Bat-Mitzvá (rito de pasaje de la niñez a adultez), la Jupá (matrimonio judío) y/o los ritos de defunción a la usanza judía. 
El siguiente cuadro refuerza el argumento de que la gran mayoría de integrantes se consideran tradicionalistas.

Pregunta: Se considera usted un judío...

$\begin{array}{lrc} & \mathbf{2 0 0 0} * & \mathbf{2 0 1 5} * * \\ \text { Muy observante } & 4.3 \% & 10 \% \\ \text { Observante } & 6.4 \% & 17 \% \\ \text { Tradicionalista } & 76.8 \% & 46 \% \\ \text { Poco observante } & 10.5 \% & 20 \% \\ \text { Secular } & 1.7 \% & 7 \% \\ \text { Ateo } & 0.4 \% & 7 \%\end{array}$

\section{*Alduncín y Asociados \\ ** Estudio realizado por el Comité Central de la Comunidad Judía de México.}

Dentro del marco de la observancia, las prácticas de mayor observancia es Pesaj (Pascual Judía) con un $93 \%$ que realiza un seder; le sigue Yom Kipur (Día del Perdón) con un 89\% y en tercer lugar se ubica el encendido de las velas en la festividad de Januka (Fiesta de las Luminarias) con un $71 \%$ (Alducín y Asociados, 2000).

En los últimos años se ha manifestado un incremento significativo en la religiosidad, lo que va acompañado del aumento en instituciones educativas de corte religioso, tanto para niños como para adultos.

Una gran variedad de productos kósher están disponibles en tiendas especializadas así como en diversos supermercados y existen varios restaurantes kósher. Tres comunidades proveen la supervisión de los alimentos kósher. 


\section{Educación}

En lo relativo a la educación escolar, una de las decisiones más importantes tomada por los inmigrantes fue establecer una escuela integral en 1924; mismo que sucedió en la mayoría de las comunidades judía de Latinoamérica. Hoy en día, se calcula que alrededor del 95\% de la población judía en edad escolar, esto es, alrededor de 9,000 alumnos, asiste a uno de los 14 colegios judíos que existen en México (http://diariojudio.com/comunidad-judia-mexico/enmexico-casi-todos-los-ninos-judios-estudian-en-colegios-comunitarios-daniel-shor/17290/). De acuerdo a los datos del año 2015, son 9,397 los alumnos que concurren a la red escolar comunitaria.

Alrededor de $30 \%$ de los alumnos no tienen los recursos para cubrir las colegiaturas por lo que reciben algún tipo de beca del colegio al que concurren o por parte de la comunidad a la que pertenecen.

La amplia red educativa incluye colegios en donde se enseña el hebreo ${ }^{9}$ e inglés, de tipo Montessori, sionistas-hebreístas, de corte religioso, yeshivot (escuelas religiosas para hombres) y kolelim. A pesar de su diversidad metodológica e ideológica, la red escolar judeo-mexicana tiene un alto nivel y se centra en los valores judaicos y, por ser de carácter integral, se ajusta a los programas oficiales dictados y reconocidos por la Secretaría de Educación Pública de México.

La comunidad Ashkenazí, en 1946, funda el Seminario de morot (maestras), con el objetivo de poder capacitar a maestras que se enmarquen dentro de la educación judía. Sin embargo, con el objetivo mayor de profesionalizar el área de los estudios judaicos en los colegios de la red comunitaria, el Vaad Hajinuj, funda la Universidad Hebraica (http://universidadhebraica.edu.mx/acerca-de-la-universidad-hebraica/quienes-somos/historia/).

\footnotetext{
${ }^{9}$ Algunos colegios, al momento de su creación, incluían la enseñanza del idish como parte de su currículo escolar. Este idioma fue suprimido a principios del siglo XXI.
} 
Considerando la educación superior, Hamui (2007) aclara que:

“Los niveles de educación de la comunidad judía mexicana han aumentado, pues en 1991, el 57\% de los judíos entre 30 y 64 años ${ }^{10}$ contaban con un título de licenciatura, a diferencia del $8.5 \%$ de los mayores de 65. La mayor frecuencia de personas con grados universitarios y de posgrado se encuentra entre los miembros de las congregaciones de Bet El y Bet Israel (49\%) y es ligeramente menor en la Kehilá Ashkenazí (38\%). Por el contrario, la presencia de personas con estudios universitarios es menor en la Comunidad Maguén David y Monte Sinaí (18 y $10 \%$ respectivamente). Sin embargo estas diferencias tienden a nivelarse en las generaciones más jóvenes”.

\section{Integración laboral}

Al llegar a tierras aztecas, la mayoría de los judíos se dedicaron al comercio (Hamui, 2007) ambulante, actividad que no requería ni gran conocimiento del idioma ni mucho capital. Como aboneros, introdujeron un sistema de crédito personal antes inexistente, poniendo así a disposición de un grupo poblacional de bajo nivel económico - obreros, servicio doméstico y empleados - cientos de artículos que antes eran permisibles únicamente para grupos de alta posición económica. Como bien se describe a continuación:

“La alternativa económica más viable para el inmigrante fue el comercio. En México la mayoría de los productos manufacturados se importaban; su precio y distribución se concentraban en los núcleos urbanos más importantes. Así, la opción para el inmigrante judio era insertarse en ese medio, llevando algunos productos a los grupos populares y los lugares apartados. El gran oficio del

\footnotetext{
${ }^{10}$ Tomemos en consideración que los individuos de estas edades son parte de una segunda generación. 
recién inmigrado fue la buhonería. Ambulantes y puesteros hicieron revolucionar el comercio en México dado que, a fuerza de competencia, fueron una de las causas principales para que artículos necesarios e indispensables antes, fuera del alcance de las clases laborantes, bajaran a precios populares" (http://diariojudio.com/opinion/breve-historia-de-la-comunidad-judia-demexico/12051/).

La depresión económica mundial de 1929-1933, tuvo fuertes efectos en México. El celo frente a los vendedores callejeros judíos y llegó a su clímax en mayo de 1931 cuando el presidente Ortiz Rubio decretó la expulsión de 250 aboneros judíos del mercado de La Lagunilla y proclamó el primero de junio como el "Día Nacional del Comercio", fecha en la que protestaron por la presencia judía (http://www.enlacejudio.com/2010/10/21/los-30's-en-mexico-epoca-de-lascamisas-doradas/).

La dinámica de estos procesos repercutió en la estructura ocupacional de los judíos, ya que al limitarse el comercio exterior por la crisis, los bienes de consumo se comenzaron a fabricar localmente, provocando el surgimiento de nuevas industrias y la diversificación de actividades. Esto se pone de manifiesto en la transición de la pequeña a la gran industria, primordialmente la textil.

Así, aunque fueron años difíciles, se logró un crecimiento económico substancial que impulsó a algunas comunidades de inmigrantes ya asentadas a ubicarse dentro de las clases sociales medias $\mathrm{y}$ altas de la sociedad mexicana.

La diversidad sectorial también se manifestó en el área laboral. En el caso Ashkenazí, una gran parte de los descendientes de los inmigrantes que se habían dedicado principalmente al comercio, cursaron estudios superiores y se profesionalizaron; mientras que los hijos de los sefaraditas y judíos orientales continuaron básicamente con la tradición comercial. 
Ciertamente, ya la tercera generación, en su conjunto, dio luz a la clase intelectual, profesional y política de la comunidad. Hoy por hoy, un significativo número de judíos mexicanos activan en diversas áreas del quehacer nacional, como en la industria y el comercio, la academia, la política, los medios de comunicación y las profesiones liberales, entre otras. En las últimas dos décadas del siglo XX se abre el mercado interno siendo que la competencia internacional provoca un reajuste en la industria textil (donde se ubicaban gran parte de los judíos) así como en el área de la construcción. Esto produce que gran parte de la población judía laboralmente activa pase de ser empleadores a ser empleados y profesionistas. En esta línea, el siguiente cuadro refleja las diversas ocupaciones a las cuales se dedican los integrantes de la comunidad judeo-mexicana y que indican los cambios que se han producido en los primeros 15 años del siglo XXI. Se ve reflejado un aumento en la mayoría de las ocupaciones, dando lugar a la ampliación y la diversidad del campo laboral ocupado por los judíos de México.

$\begin{array}{lll}\text { Ocupación: } & \mathbf{2 0 0 0} & \mathbf{2 0 1 5}^{* *} \\ \text { Dirigente privado } & 0.5 \% & \text { Sin datos } \\ \text { Intelectual } & 3.5 \% & 10 \% \\ \text { Empresario } & 25.1 \% & 45 \% \\ \text { Profesional } & 8.8 \% & 18 \% \\ \text { Empleado privado } & 8.7 \% & 27 \% \\ \text { Burócrata } & 0.3 \% & \text { Sin datos }\end{array}$

\section{*Alduncín y Asociados \\ ** Estudio realizado por el Comité Central de la Comunidad Judía de México.}

Progresiva y paralelamente al ascenso económico, el centro de la Ciudad de México, que había sido el primer punto de residencia para los judíos (así como para otros grupos inmigrantes, particularmente por su bajo costo), dejó de serlo cuando una numerosa cantidad de ellos se mudó a zonas de mejor nivel. Ante esta movilidad geográfica, un porcentaje significativo decidió establecerse en el poniente de la ciudad, conformando así un perímetro habitacional concentrado en colonias residenciales de la misma, mayormente en las colonias Condesa y Polanco (21.6\%). 
También migran a colonias más alejadas como Las Lomas (28.6\%), La Herradura (16\%) y Tecamachalco (21.8\%). ${ }^{11}$ Al proseguir la ramificación de la ciudad misma, y nuevas construcciones tanto de zonas habitacionales como comerciales de alto nivel, los judíos nuevamente migran a esos nuevos espacios geográficos. Ejemplo de ellos son Interlomas, y la zona de Lomas de Vista Hermosa, El Chamizal y Santa Fe.

Las instituciones comunitarias, por su parte, también se trasladaron a estos mismos espacios geográficos con el propósito de mantener la unidad comunitaria y que los servicios otorgados fueran de fácil acceso y alcance.

\section{Relación con la sociedad mexicana}

Aunque cada sector mantiene autonomía en asuntos internos, de igual forma coopera con los demás para la resolución de los problemas comunes. Bajo esta línea existe una institución cúpula que en la actualidad agrupa a todo el colectivo judeo-mexicano: el Comité Central de la Comunidad Judía de México (CCCJM). Creado en 1938, como una asociación pro-refugiados judíos de Europa, dio respuesta a las necesidades de cohesión de los sectores comunitarios provenientes de diversas regiones del orbe. Al punto que, en septiembre de 1939, dicho Comité Pro-Refugiados se convirtió en la representación oficial de la totalidad de la comunidad judía en México, sin distinción de origen.

A la fecha, el CCCJM, integrado por todos los sectores comunitarios, responde al imperativo de cimentar vínculos y abrir canales de comunicación con México y sus instituciones. A su vez, asegura que, dentro de la diversidad interna prevalezcan la unidad y una vida comunitaria integral.

${ }^{11}$ La fuente de todos los porcentajes señalados son de Alduncín y Asociados (2000). 


\section{Antisemitismo}

El antisemitismo en México nunca ha sido una política oficial, aunque no han faltado actores políticos que en diversos momentos han manifestado argumentos antijudíos. No ha existido una discriminación formal avalada por el gobierno y tampoco se han presentado acciones violentas de dimensión significativa. No obstante, el antisemitismo si ha estado presente en la sociedad mexicana.

En el México moderno el antisemitismo tiene sus orígenes a finales de la década de los veinte. En 1929-30 la depresión económica favoreció el ataque en contra de los extranjeros. En octubre de 1930 fue fundada la Liga Nacional Antichina y Antijudía, que buscaba "contrarrestar la acción cruel y sangrante de los judíos, que destruían el comercio y las actividades económicas de los mexicanos". Se generalizaron protestas en contra de la presencia de los judíos en la vida comercial del país.

En 1934 se funda en la ciudad norteña de Mexicali el grupo "Acción Revolucionaria Mexicanista" que operaba a través de su unidad paramilitar "Las Camisas Doradas", que fue suprimida por el gobierno en 1935 (http://www.enlacejudio.com/2010/10/21/los-30's-en-mexicoepoca-de-las-camisas-doradas/).

Junto con la actividad de la derecha de tipo secular, grupos de derecha religiosos surgieron como representativos de actitudes xenófobas y antisemitas. Este fue el caso del Sinarquismo, la Acción Católica Mexicana, los Tecos y la Asociación Católica de Jóvenes Mexicanos, entre otros.

Esta tendencia se modificó cuando México declaró la guerra contra las potencias del Eje en mayo de 1941. A partir de entonces, distintos grupos antifascistas lucharon abiertamente contra el fascismo y el nazismo y manifestaron su apoyo a los judíos. 
Para el año de 1944 el Comité Central Israelita y la B'nai B'rith crearon Tribuna Israelita (http://tribuna.org.mx) para organizar en forma homogénea y coordinada la lucha en contra del antisemitismo.

En junio del 2003 el presidente Vicente Fox promulgó la Ley Federal para Prevenir y Eliminar la Discriminación, previamente aprobada por unanimidad por el Congreso y el Senado, la cual en su artículo $4^{\circ}$ establece que: “También se entenderán como discriminación la xenofobia y el antisemitismo, en cualquiera de sus manifestaciones".

La participación de Tribuna Israelita y del Comité Central fue relevante en el proceso de consolidación de esta ley, la cual representa un gran avance en el reconocimiento de México como una sociedad plural y diversa donde el respeto a las diferencia debe de ser la regla y no la excepción.

En la actualidad el antisemitismo, particularmente proveniente de grupos de la izquierda mexicana, se manifiesta principalmente a través de grafitis y pintas, así como en los medios masivos de comunicación. A raíz del conflicto palestino-israelí, se incrementó la cobertura negativa en la cual se describe al Estado de Israel como una nación violenta, con una política racista y genocida. Estos artículos, velada o abiertamente antisemitas o antisionistas, han afectado la imagen del judío mexicano.

\section{Sionismo, sus instituciones e Israel}

En la década de los cuarenta, particularmente con la creación del Estado de Israel en 1948, el sionismo pasó a ser un identificador con mayor poder de cohesión comunitaria. Se generó una cultura enfocada al naciente hogar judío, la cual se hizo presente en la mayor parte de la instituciones judías, inclusive aquellas que no eran sionistas específicamente. 
El sionismo sin duda ha ejercido gran influencia a nivel comunitario. No obstante, a pesar de que la identificación con Israel existe, (un 83\% atribuye gran importancia a Israel) el número de judíos que ha hecho aliá (emigrado a Israel) es relativamente bajo: de 1948 a la fecha han emigrado a Israel 4,000 personas y alrededor de 2,000; la mitad han regresado a México.

No obstante, para el año 2000, más del 70\% de los judíos mexicanos han visitado Israel entre una y cuatro veces y sólo el 16\% no lo conoce, mientras que para el 2015 esta cifra subió al 89\% de quienes la han visitado y $11 \%$ nunca han estado en Israel. Esto ha sido posible gracias a diversos programas como son los viajes organizados por las escuelas judías al terminar tercero de secundaria (a los 15 años) durante el verano con el fin de conocer y familiarizarse con Israel, su gente y su entorno.

Además se realizan otros viajes bajo proyectos específicos como podrían ser los de índole deportivo -las Maccabeadas-, de capacitación académica -particularmente para los morim (maestros) de las escuelas judías-, de turismo y la hajshará (año en Israel al terminar los estudios preparatorios).

El apego a Israel se manifiesta, de hecho, en otras formas. Más allá de las instituciones propiamente sionistas como la Agencia Judía, la Federación Sionista, el Keren Kayemet (Fondo Nacional Judío) y el Keren Hayesod (United Israel Appeal), existen diversas organizaciones que indudablemente están ligadas a Israel como lo son los Amigos de las Universidades de Israel, las organizaciones femeninas como WIZO, Na'amat y Hadassa, entre otras. Entre las labores de estas instituciones está el apoyo a diferentes proyectos que se implementan en Israel así como la promoción de intercambios culturales y científicos. 
Dentro del ámbito educativo, los colegios de la red escolar judeo-mexicana, consideran el vínculo con Israel como uno de los elementos centrales de su ideario, particularmente en lo referente a la relación con los judíos de la diáspora. En el campo de la educación informal, que incluye básicamente a los movimientos juveniles de corte sionista, a pesar de que éstas cuentan con poca concurrencia, sin lugar a dudas han tenido su influencia. Es interesante destacar que gran parte de los individuos que optan por la alía, han frecuentado estos movimientos.

\section{La Comunidad judeo-mexicana a finales del Siglo XX}

La década de los noventa fue un periodo de muchos cambios a nivel político, económico y social en México. Se puede considerar que la palabra clave para entender y explicar las modificaciones en las percepciones y en los patrones de conducta tanto dentro como fuera de la comunidad judía en este país es la apertura.

\section{Cambios políticos}

Ya desde los últimos años de la década de los ochenta se comienza a percibir un proceso de transformaciones políticas. Ejemplo de esto es la victoria de Vicente Fox, candidato del Partido de Acción Nacional en julio de 2000, terminando así siete décadas de hegemonía del Partido Revolucionario Institucional.

Bajo una línea pluralista, en el año de 1992 se reforma el artículo 4to. Constitucional para darle aceptación por primera vez a la composición pluricultural del Estado Mexicano.

La apertura de la estructura política generó una mayor presencia de entidades no gubernamentales. Como resultado, diversos segmentos de la sociedad civil que previamente se sentían marginados, entre ellos el grupo judío, comenzaron a tener mayor participación en la toma de decisiones, es decir, pasaron a ser actores en lugar de simples observadores. La comunidad judía no fue la excepción, y prueba de ello ha sido el creciente número de jóvenes 
funcionarios judíos que son parte activa de la administración pública inclusive a nivel ministerial.

Cabe destacar que en lo que a orientación política se refiere, la comunidad Judía de México mantiene un carácter heterogéneo, no se vota en bloque.

\section{Cambios económicos}

El año de 1994 se despidió con una devaluación monetaria que repercutió en todos los niveles socioeconómicos del país. A su vez, aumentó el índice de desempleo, se incrementó en forma alarmante el crecimiento en los índices de inseguridad particularmente en la ciudad de México y se manifestó un alto grado de pauperización de las clases medias.

Esta crisis afectó a un amplio sector de la comunidad judía, por lo que la colectividad tomó medidas para auxiliar a quienes más lo necesitaran. Consecuentemente, aumentó el número de becas otorgadas a alumnos en la red escolar judía. Así mismo, se creó "Activa”, institución cuya función principal es proveer una bolsa de trabajo para quien así lo requiera y se implementó el “Activa Business Center”, con el objeto de reactivar económicamente a personas sin empleo o de bajos ingresos, así como capacitar y asesorar a pequeños y medianos empresarios. Todos estos factores son indicadores que ponen de manifiesto el deterioro económico que también aquejó a este grupo.

\section{Nuevas necesidades, nuevas instituciones}

Tanto en el plano comunitario como en el de orden individual, el judío ve ante sí mayores posibilidades de participación dentro de la sociedad mexicana En lo relativo a la visibilidad, indudablemente se denota una mayor presencia en centros de poder, tanto a nivel institucional como de participaciones individuales -judíos que no participan representando a la comunidad. Hay participación en Conapred (Consejo Nacional para Prevenir y Erradicar la Discriminación) y Copred (Consejo para Prevenir y Erradicar la Discriminación de la Ciudad de México). 
Participan en distintas organizaciones no gubernamentales ( $\left.\mathrm{ONG}^{\prime} \mathrm{s}\right)$ y destacan en el área intelectual y profesional, la educación y la cultura. A su vez, promueven la creación de fuentes de empleo, programas de capacitación, de educación y de ayuda directa; construcción de viviendas para grupos marginados.

A nivel interno, han proliferado diversas instituciones comunitarias con afán de colaborar en el mejoramiento de las condiciones de vida de sus miembros, las cuales en gran medida se fundaron a raíz de una mayor apertura del entorno. Entre ellas se encuentran:

- "Umbral", instancia que trata prevención y tratamiento de adicciones.

- "Kadima", dedicado a integrar a la sociedad a individuos con capacidades especiales.

- Fundación "Menorah", problemas de violencia intrafamiliar.

- OSE y Dam Hatzalá, que proveen servicios médicos a personas de escasos recursos económicos.

- Eishel, Beyajad y Kol Hanisayón, instituciones abocadas a dar servicio al adulto mayor.

Todas estas organizaciones son consideradas de carácter intercomunitario: creadas con el fin de ser utilizadas por todos los miembros de la comunidad judía. Hay que destacar que paralelamente, cada uno de los sectores comunitarios, a su vez, brinda servicios de salud y asistencia social, entre otros, a sus propios integrantes. 


\section{Asimilación a la sociedad mexicana}

La cohesión comunitaria y la segregación frente a la sociedad mexicana aunado a las sólidas redes institucionales -particularmente la escolar- han permitido que el grado de asimilación, medido a través del índice de matrimonios mixtos o exogámicos, sea uno de los más bajos de la diáspora.

De acuerdo con los resultados obtenidos del estudio sociodemográfico del 2000 el $94 \%$ de los matrimonios son de tipo endogámico, es decir, que ambos cónyuges son judíos por nacimiento. Es interesante destacar que del $6 \%$ de parejas exogámicas (también denominados matrimonios mixtos), el 99\% observa en su hogar la religión judía.

A pesar de estos indicadores positivos, debemos de observar cuales son las percepciones sobre este tema por los mismos integrantes de la comunidad. Para el año 2000 un 54\% de los encuestados no acepta los matrimonios mixtos cuando para el 2016 se obtuvo un 59\% con un NO rotundo a los matrimonios exogámicos.

Para ese mismo año un $46 \%$ que sí está de acuerdo, de ellos un 36\% bajo la condición de que se lleve a cabo la conversión, siendo que para el 2015 un 22\% la acepta pero con conversión, mientras que un $19 \%$ la acepta sin conversión,

La diferencia entre ambas encuestas, con más de 15 años de diferencia, indica que la tendencia de baja asimilación dominante en las generaciones pasadas, continua siendo alta aunque se vislumbra una exigua apertura frente a la posibilidad de permitir que personas no judías se integren a la comunidad, con y sin conversión.

\section{Desafíos comunitarios del siglo XXI}


El colectivo judeo-mexicano pone de manifiesto, en términos generales, una alta pertenencia comunitaria de sus miembros, reforzado sin duda por las instituciones comunitarias que, desde sus orígenes, han tratado y con relativamente bastante éxito, cubrir gran parte de los ámbitos de la vida del individuo dentro de un ambiente judío. La socialización, tanto por parte de la familia como de las organizaciones, ha sido un factor clave y esencial en esta tarea.

A raíz de todo lo expuesto anteriormente se puede concluir que un fuerte sentimiento comunitario y la presencia de una cadena de relaciones comunitarias refuerzan la pertenencia al grupo. Se refleja un fuerte sentido de etnocentrismo que mantiene a la comunidad al margen de la asimilación. Por lo tanto podemos asumir que una reducción del grupo a través de la asimilación es un proceso poco visible aunque sí en aumento.

Sin embargo, la comunidad judía de México no está fuera del rango de influencia de factores externos, por el simple hecho de ser parte de un conglomerado mayor, el continente latinoamericano. América Latina ha pasado por periodos de inestabilidad tanto en lo económico como en lo político y México es parte de la región y por lo tanto ha tenido su alcance. De forma específica se debe de agregar que México tiene sus propias complicaciones: un grado de inseguridad que va a la alza, la presencia del narcotráfico que afecta de forma desigual a gran parte de la sociedad, la economía y la política mexicana, y otras variables que influyen tanto en la migración (USA y Canadá como primeras opciones e Israel) y otros nuevos desafíos.

Entre los desafíos se encuentran:

La pauperización - La crisis económica por la que atraviesa el país ha afectado a los judíos, cuyo costo de vida es alto en relación a gran parte del resto de la población. Se ha incrementado el número de familias que reciben becas escolares, asistencia médica y ayuda financiera. 
Quien quiere ser parte de la comunidad judía tiene que cubrir cuotas de partencia comunitaria y altas colegiaturas. Para vivir en la zona donde se encuentran los centros comunitarios y las escuelas también es necesario pagar costosas rentas.

Las comunidades y sus instituciones tendrán que implementar soluciones creativas con el fin de lograr que sus integrantes se mantengan dentro del núcleo y continúen llevando una vida judía.

Juventud - Diversas organizaciones comunitarias se han abocado a cubrir las necesidades de los jóvenes judeo-mexicanos: movimientos juveniles, asociaciones universitarias y grupos socioculturales. Ciertamente, la juventud es el grupo de mayor vulnerabilidad frente a la deserción grupal porque, en su mayoría, después de terminar sus estudios escolares en un ambiente judío, ingresan a las universidades e incrementan su relación con el entorno no judío. Por ende, las instituciones deben enfocarse particularmente a este sector, ofreciendo mayores espacios de socialización entre ellos.

Asimilación - Conforme aumenta la apertura y se legitime aún más el evidente carácter plural de México, se incrementa la interacción del grupo judío con la sociedad circundante en todos los ámbitos. Este proceso favorece la interacción de los judíos con la sociedad general pero a su vez puede fomentar la deserción voluntaria de varios de ellos. Por ello, aunque actualmente el grado de asimilación es bajo, no por ello se está exento de tal riesgo.

Religiosidad - En los últimos veinte años, en la comunidad judeo-mexicana en particular y el mundo judío en general, se ha manifestado un incremento de la religiosidad de algunos de sus integrantes. Esto implica, a nivel macro, un mayor fortalecimiento entre los grupos religiosos, los cuales no siempre son el grupo mayoritario dentro de las comunidades judías lo que provoca conflictos y luchas ideológicas internas. Por otro lado, a nivel micro, conlleva la fragmentación de aquellas familias donde solo alguno de sus miembros se torna religioso y esto trae conflictos internos difíciles de conciliar. 
La Comunidad Judía de México enfrenta diversos desafíos a los que tendrá que dar respuesta para garantizar su continuidad. Siendo una comunidad vigorosa y activa, la búsqueda de la prolongación judía ha sido la línea de partida y la guía esencial que le ha permitido seguir adelante y avanzar por el siglo XXI con fuerza y madurez.

\section{Bibliografía}

Aguiar de Peniche, A. M. (2000) México-Israel, Tierras Prometidas, Grupo Impresor Unicornio.

Alduncín y Asociados (2000) Estudio Sociodemográfico de la Comunidad Judía en México. A solicitud del Comité central de la Comunidad Judía de México. Inédito. México.

Bókser-Liwerant, J. (dir.) (1992) Imágenes de un encuentro. La presencia judía en México durante la primera mitad del siglo XX. Tribuna Israelita, Comité Central Israelita de México, Universidad Nacional Autónoma de México y Multibanco Mercantil Probursa, México.

Dabbah Askenazi, I. (1982) Esperanza y Realidad. Raíces de la Comunidad judía de Alepo en México. Editorial Libros de México, México.

Della Pergola, S. \& Lerner, S. (1995) La población judía de México: Perfil demográfico, social y cultural. Instituto Abraham Harman de Judaísmo Contemporáneo de la Universidad Hebrea de Jerusalén, Centro de Estudios Demográficos y de Desarrollo Urbano de El Colegio de México, Asociación Mexicana de Amigos de la Universidad Hebrea de Jerusalén, México.

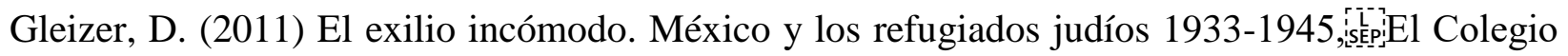

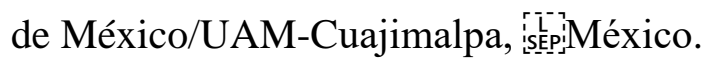

Gojman de Backal, A. (2000) Camisas, escudos y desfiles militares. Los Dorados y el antisemitismo en México (1934-1940). Fondo de Cultura Económica, México. 
Gutiérrez Zúñiga, C. (1995) La comunidad israelita de Guadalajara. El Colegio de Jalisco, México.

Hamui Sutton, A. (2003) Transformación en la religiosidad de los judíos en México tradición, ortodoxia y fundamentalismo en la modernidad tardía. Tesis doctoral, Universidad Iberoamericana, México.

Hamui, L. (2007) "Mexico”. Encyclopedia Judaica. Eds. Michael Berenbaum y Fred Skolnik. Thomson Gale. Vol.14. 2nd ed. Detroit: Macmillan Reference USA, pp. 137-146.

Liebman, S. B. (1971) Los judíos en México y América Central. Fe, llamas Inquisición. Siglo XXI Editores.

Roitman, D. (2005) Identidad Colectiva y Consenso Cultural: El Grupo Judío en la Ciudad de México a Principios del Siglo XXI, un Estudio de Caso. tesis de doctorado, Universidad Nacional Autónoma de México.

Sourasky, L. (1965) Historia de la Comunidad Israelita de México 1917-1942. Imprenta Moderna Pintel, Cdad. De México.

Toro, A. (compilador) (1982) Los judíos en la Nueva España. Fondo de Cultura Económica, México.

Smeke, J. y varios (1999) Historia de una Alianza. Impresión y encuadernación: Turmex, Cda. De México.

Enciclopedia Judaica Castellana “México (Estados Unidos Mexicanos)”, pp. 426-462.

Estudio realizado por el Comité Central de la Comunidad Judía de México, 2015.

\section{Bibliografía en línea}


http://tribuna.org.mx/presencia-judia-en-mexico

Guadalupe Zárate, La comunidad judía en México. En

http://www.estudioshistoricos.inah.gob.mx/revistaHistorias/wp-content/uploads/historias_04_4960.pdf

Zack de Zukerman, C. Una recepción sorpresiva, polacos refugiados de guerra en México. pp.1415. En:

https://books.google.cl/books?id=kZVk8aIpJfoC\&pg=PA14\&lpg=PA14\&dq=Invitacion+de+plu tarco+Elias + calle $+a+l a+i n m i g r a c i o n \& s o u r c e=b l \& o t s=v j B 9 D V t-P-$ \&sig=ewyar4TbCbmhkHWlOp5DDraIvEs\&hl=es-

419\&sa $=X \&$ redir_esc $=\mathrm{y} \# \mathrm{v}=$ onepage $\& \mathrm{q}=$ Invitacion $\% 20 \mathrm{de} \% 20$ plutarco $\% 20 \mathrm{Elias} \% 20 \mathrm{calle} \% 20 \mathrm{a}$ $\% 201 \mathrm{a} \% 20$ inmigracion $\& \mathrm{f}=$ false

Yankelevich, P., México, país refugio: la experiencia de los exilios en el siglo XX, pp. 125-126. En https://books.google.cl/books?isbn=9707220961

http://diariojudio.com/autor/vaad/

http://universidadhebraica.edu.mx/acerca-de-la-universidad-hebraica/quienes-somos/historia/ http://diariojudio.com/opinion/breve-historia-de-la-comunidad-judia-de-mexico/12051/ http://www.enlacejudio.com/2010/10/21/los-30's-en-mexico-epoca-de-las-camisas-doradas/ http://diariojudio.com/comunidad-judia-mexico/en-mexico-casi-todos-los-ninos-judios-estudianen-colegios-comunitarios-daniel-shor/17290/ 
El educador judío latinoamericano en un mundo trasnacional. Bokser, Della Pergola, Senkman y Goldstein. Centro Liwerant para el Estudio de América Latina. Universidad Hebrea, pp. 25-30. Fuente: educadorjudio_informe.epub

http://www.enlacejudio.com/2011/01/07/numeros-judios/

http://tribuna.org.mx/presencia-judia-en-mexico/ 